the surface. These defects now migrate into the lattice and increase in concentration until saturation is reached, and metal or lower oxide forms as a new phase. In roasting sulphides one would similarly expect that oxygen ions would first be formed on the surface, creating cation holes within the lattice. This would be followed by destruction of the positive holes as oxides of sulphur are eliminated, and the resultant building of oxygen into the lattice in place of sulphur. Studies of the roasting of copper sulphides by a new nethod reported by Prof. E. A. Peretti (Notre Dame, Indiana) are in line with this picture, for they show that the reaction proceeds directly from cupric to cuprous sulphide and finally to cuprous oxide, and not via the formation of sul. phates as previously believed.

Our present understanding of liquid slags is far from adequate. This can be attributed partly to the fact that ionic melts in general have received little attention from the physical chemist, and partly to the great difficulties which arise in making controlled experiments with materials which attack containers of all types. As Dr. F. D. Richardson (British Iron and Steel Research Association) pointed out, our ideas of liquid slag structures are based essentially on our knowledge of the structures of crystalline silicates, phosphates and aluminates, and the recognition that the liquid state differs from the solid mainly in lacking any long-range order. This picture is corroborated by X-ray work on silica glasses, which have been shown to consist of random networks of silicate tetrahedra with metallic cations located in the holes between them. The chemical potentials of the components of slags have in some cases been determined by slag-metal equilibrium measurements. For binary systems they can be obtained less directly from phase diagrams, and interesting results derived in this way were reported by Prof. M. Rey (École des Mines, Paris). The standard states for some of the oxides and sulphides of importance in slags present a problem in cases such as ferrous oxide ( $\mathrm{FeO}$ ) and iron sulphide ( $\mathrm{FeS})$, which can exist over wide ranges of composition depending on the equilibrium oxygen or sulphur pressures. Although failure to take account of such non-stoichiometric variations may not lead to large errors in total free energy changes, it was stressed by Dr. G. M. Willis (Melbourne) that large errors may be caused in the partial molar free energies of com. ponents in slag melts. An ionic view of slags has been developing in recent years, and although, as Prof. E. A. Guggenheim (Reading) pointed out, it is irrele. vant, so far as slag-metal equilibria are concerned, whether the various atoms or atom groupings are ionized or not, knowledge of the ionic constitution is helpful in developing a detailed model of slag melts, and may, indeed, be of practical importance in arc furnaces. Dr. J. A. Kitchener, Dr. J. O'M. Bockris and Messrs. J. Tomlinson and S. Ignatowicz (Imperial College, London) reported measurements of the electrical conductivity of binary silicate melts, which indicate that the conduction is mainly ionic. It increases more than one-hundredfold at the melting point for calcium and manganese silicates, and shows a temperature coefficient compatible with the view that the conductivities are due to the small, relatively mobile cations, and the viscosities to the large, relatively immobile anions.

All those concerned with the application of physical chemistry to process metallurgy owe a great debt to the Faraday Society for arranging this discussion.
Apart from the stimulating effect of bringing together workers in this field from many laboratories and many different countries, it has brought the criticisms and ideas of physical chemists outside this field to those who are now working in it. It is to be hoped that the discussion will also stimulate physical chemists generally to take a new interest in the fundamentals of some of these interesting high. temperature systems.

F. D. RICHARDSON

\section{VETERINARY EDUCATION : DEVELOPMENTS AT CAMBRIDGE}

\section{By Dr. JAMES T. EDWARDS}

$\mathrm{T}$ HE address before us* breathes a freshness of outlook which bestirs the imagination of those who have watched a public awakening into the need for finding a healthy solution to a problem which, since the onset of the Industrial Revolution, and even before then, has been treated in Great Britain, to its sad discredit, with sore neglect.

This problem is concerned not only with the 'doctoring of animals', the pursuit which the ordinary member of our public associates with the designation 'vet.'. That in itself, it can never be too strongly emphasized, is an art which calls forth all the skill that is born of long and close experience, all the powers of keen and careful observation, and all the moral virtues of sympathy and kindliness which the human faculties can muster. It is an art which in the course of its long history has seen its periods of great triumph and of respect in the eyes of society, and its periods of utter debasement. Its triumphant periods have been within the histories of great empires at the height of their glory-the Buddhist, the Byzantine, and the Arab; and, let us hope, the British Commonwealth, as it is now marching to higher destiny, will be added to them. One of the worst, if not the worst and most infamous, of the periods in which the art suffered degradation was that in which the Church dominated thought and conduct in the Western world-the Dark Ages. Let us insist at once that this decline in respect for the art did not owe its origin to the Christian ethic, with its dominant note of 'charity'. Compounding for it a doctrine in which the ingredients were not incompatible with persisting Mediterranean cults and contained an infusion of neo-Platonism with some tincture of Christianity, the early Church Fathers, in their wisdom, shrewdly mindful of means of fostering moral uplift among peoples as they were at that time, founded a powerful hierarchy. This hierarchy increasingly in its interest played hard on the Platonic concept of the 'soul' as a higher state of being, which was immortal, and did not pertain to the 'beasts', which in their suffering were therefore denied both pity and mercy. (This theme has been well developed recently by the eminent French scholar and experienced veterinarian Emmanuel Leclainche in his book, "Histoire de la Módecine Vétérinaire" (Toulouse : Office du Livre, rue Alsace. Lorraine, 42 ; 1936).) The human physicians were hence eagerly absorbed into the Church, and their learning became that of the Church, disdaining craftsmanship and the knowledge which Plato's

- Veterinary Education. An Inaugural Lecture. By Prof. W. I. B. Beveridge. Pp. 40. (Cambridge: At the University Press, 1948.)
18. 6d. net. 
contemporary, Aristotle, had proved could be so richly garnered for the benefit of mankind from observation on the 'brute creation'. It was not until well into the eighteenth century that craftsmanship became elevated in esteem as a branch of the healing art with the rise of the surgeons from their lowly standing of barber-surgeons. Nothing of this sort had occurred in the older civilizations where, in the Arab Empire, for example, the arts of healing, both of man and animal, were taught side by side, with equal respect, in her great universities, from Baghdad to Salamanca.

After the fall of Rome, and the lapse into disuse of her magnificent road communications with the lethargy that then beset humanity, the Western world broke up into isolated communities, governed, or tyrannized, by baronial courts, the chief officials in each of which were the chamberlains, seneschals and marshals. It was to the marshals that was consigned the important office of charge of the cavalry, comprising both the management and treatment of the horses. From about the eighth century B.c., beginning in Babylonia, right up to the First World War, the use of cavalry in warfare, supplying as it did to this vital enterprise mobility and striking power, had been a main concern of rulers and States. Epidemic disease among horses, of which the chief was glanders, hampered campaigns and so encompassed gravely their existence. During the period of the Crusades, with the discovery of the art of horse-shoeing and the need for preserving cavalry on the march for long distances, a new class of menial assistants to the marshals arose who, besides acquiring proficiency in the craft of making and nailing-on (ferrer) iron horseshoes, were also entrusted by their masters with the more laborious duties in treatment, such as the dressing of wounds and drenching of potions. These farriers, as they came to be called, soon, in the way of human nature, supplanted their trusting, well-bred masters, the marshals, usurping as they did in France a title common to both-maréchal-ferrant. Doubtless among them there were to be found many observant and worthy practitioners; but, on the whole, throughout Western countries they came to be looked upon as an ignorant class recruited from the most depraved strata of the public such as the knacker. men and hangmen. The brutality of their treatments, matched only by their exorbitant charges as fees, was such that, as has been well said (McFadyean, 1923), the most fortunate animals before the opening of the veterinary schools in Western Europe during the latter half of the eighteenth century were those which escaped notice by that class.

There was no dearth of good literature to be consulted, such as the remarkable symposium recorded in the "Hippiatrika" by the Byzantine hippiatrists, and emended and plagiarized in various ways throughout the Middle Ages by successive authors. Yet, strangely, the literature which was produced and obtained a large circulation, such as that of the notorious impostor, Gervase Markham (1568-1637), was of the vilest, all diseases being assigned meaningless names and little description; but, for all there was an 'infallible' cure that had been a long-guarded 'secret', and was a shameful polypharmacy calculated to assuage and exploit superstition and credulity.

An exception to this lamentable story of the West was to be seen in Spain during the days of her greatness as a world power, where the Catholic monarchs, after the expulsion of the Moors, were careful in their own interest to preserve what was best from the
Arab civilization they had conquered. Among this best was a well-educated and highly disciplined profession ministering to the domesticated animals, in particular the horse, to the governing body of which profession (the Protoalbeitariat) they graciously accorded their own patronage. It was not until 1813 when the Spanish Cortes, meeting at Cadiz, decided, in an excess of liberalism, to abolish all corporate institutions that this valuable profession became disrupted, never again to recover its former dignity and usefulness.

Meenwhile, concern was being felt in another way with the appallingly low state into which the healing art ministering to the animal world in the West had fallen. This concern was being felt not only by rulers and States but also by those whose interest it was to preserve the herds and flocks upon which the lives and prosperity of peoples so largely depended. From time immemorial, recurrent waves of devastating plagues among the domesticated animals had been known, the most serious of these being cattle plague (or rinderpest). As evidence of the concern of rulers may be cited that of Frederick the Great, who on return in 1767 from his Silesia campaign in the Seven Years War and fresh from witnessing the devastation caused by cattle plague and the consequent horrors suffered by the civil population, requested the Medical Faculty in Berlin to draw up plans for the opening of a veterinary school. This the professors of the Faculty did reluctantly, but added at once, almost reproachfully, that it was hoped it was not to be further expected of them to soil their hands in the carcases of beasts. The low ebb of affairs in this respect in Britain was decried by the wise and observant physician, Sir Thomas Browne (160582) (Smith, F., "The Early History of Veterinary Literature and its British Development", 1, 311 ; 1919), the author of "Religio Medici", who in his book "Pseudodoxia Epidemica" bewailed the ignor. ance of the 'common farriers' to whom only recourse could be had by stockowners at the time, and appealed for the raising of a new class whom he designated by a term new to the language, 'good veterinarians'. Drawing on his massive classical scholarship, he had introduced a word which was held in repute in the earlier history of Rome, signifying a cattle husband. man. The solid farming peoples from whom Rome then derived her man-power were much attached to their cattle, the older, more mature, of which (the veterini) they prized for their tillage, their respected attendant being the veterinarius.

In Britain, concerm was felt not so much by its rulers or its Government, as by the rising agricultural societies, one of which, the Odiham Agricultural Society of Hampshire, initiated the movement for starting veterinary education in England, while, later in Scotland, the Highland and Agricultural Society lent its powerful patronage to William Dick when he started a school in Edinburgh in 1823.

A Board of General Officers, sitting in London in 1796, decided that the best term to use for the educated recruits drafted urgently from the London Veterinary College, that had been opened in 1791, for care and treatment of cavalry and artillery horses in the Napoleonic War was 'veterinary surgeons', to distinguish them as a corps apart from the surgeons, who until then had been displaying keen interest also in that work. The designation was afterwards taken up enthusiastically by fellow practitioners among the civil population. As the late Sir Frederick Smith (1857-1929), the meticulously accurate veter- 
inary historian, rightly insisted, however, the designation is a misnomer, for the practitioner of the healing art among animals has ever been more of a 'physician' than a 'surgeon'. Prof. Beveridge in his address contends that the name was not "a happy choice". We may agree, to some extent, however, with Leclainche in concluding that the very lack of precise meaning in it commends it ; and, further, it has a safe position in language inasmuch as most countries have introduced it into their language and so it has gained the sanction of widespread usage. The powerful sanction of usage need not, however, we can now better realize, compel ultimately refusal to employ some more explicit name when that is really needed. In Britain, for example, what was long called the Veterinary Branch of the Board (now the Ministry) of Agriculture has come to be known as the Division of Animal Health. From its founda. tion in 1884, a similar great organisation in the United States has been known as the Federal Bureau of Animal Industry.

The Charter of Incorporation of Veterinary Surgeons, 1844, which gave legal recognition to the title of 'Veterinary Surgeons' as the exclusive designation of those who qualified from the veterinary colleges after passing an examination held by an elected Council of their body, was not confirmed by Statute until the passing of the Veterinary Surgeons Act, 1881, when in protecting the title 'veterinary', the exclusive right to use which had been allowed to lapse, a considerable body of unqualified people were brought on the register as 'Existing Practitioners'. The Act did not debar anyone, however, from undertaking veterinary practice so long as he did not use the title. In some progressive countries for a long time the veterinary profession has enjoyed the privileges of a 'closed shop', and it is one of the aims of the Veterinary Surgeons Act which has just become law to secure the same privileges for the veterinary profession in Great Britain.

To revert to the low ebb of affairs generally prevailing in Europe until well into the eighteenth century : there was, as we have seen, a widespread and periodically deeply felt need for the supply of enlightened and skilled men to control pestilence among animals; and, as the late Sir George Newman rightly said in regard to his own calling, "pestilence has always been the opportunity of medicine". It is an opportunity, as all who have had intimate experience of the subject well know, that has to be quickly seized, for the public soon forgets once the danger is over. It has to be remembered, too, that in human medicine matters were little better, for until 1745 there was no formal medical education in England, and thenceforward until 1782 what little that was given was imparted at private schools. Now and again, there were forthcoming highly gifted men, without special training for the purpose, who as if by intuition divined and applied wholly appropriate measures for controlling disease. For example, in 1714, Thomas Bates, surgeon to the King, by resolutely applying the model system of 'stamping. out' contagion outlined by the Papal physician, Lancisi, in 1711, succeeded in eradicating quickly cattle plague from England. When about thirty years later the disease reappeared, recurring after. wards until near the close of the century, when war prevented importations of live cattle, Bates's suc. cessful experience had been forgotten or overlooked. The natural disappearance of important cattle epidemics, it may be stressed here, from Great
Britain during the last part of the eighteenth century and until the beginning of the fifth decade in the nine. teenth century was largely responsible for Government and organised societies losing interest for a long time in veterinary education and for its consequent falling after its inception in England in 1791 into unworthy and incompetent hands, a setback from which it never fully recovered, even to this day. James Clark, of Edinburgh, 'Farrier' to the King for Scotland, who, according to Sir Frederick Smith, may "well and truly be described as the father of Veterinary Hygiene, not only in this country but in Europe", published, in 1788, a work on the "Prevention of Disease" which is a revelation. It was doubtless the application later of the principles of ventilation to stables advocated by Clark which brought about the rapid decline of glanders and other respiratory infections in Army horses.

What is important so far as we are concerned in criticizing the work under review is-what is not emphasized in it or, for that matter, in any recent document-that the universities throughout Christendom themselves took no heed whatever of this prevailing deplorable state of affairs, for which learning and inquiry of the highest onder were sorely needed. They were, on the whole, not only apathetic, but disdainful, even hostile. Several examples could be readily given if space permitted.

It was not until the twentieth century had opened that the universities awakened, and then almost everywhere in the world, to a realization that the pursuit was worthy of the exercise to the fullest of such powers as were possessed by men and women of first-rate intelligence and general education, and that they must no longer keep aloof. Of all the larger territories, Australia, at Sydney and Melbourne (though this latter school is now closed), has shown outstanding willingness to aid advance of the pursuit by its universities. But already there is much to record in the experiences of several other countries upon the association of the universities with veterinary teaching. Britain has lagged; but there have been peculiar difficulties.

How, in the meantime, veterinary education developed has been well touched upon in the address under review, and it would exceed the compass of a short article even to give a bare summary of the complicated story. The time was doubtless ripe during the latter half of the eighteenth century for it to begin, as it did, with the opening of a veterinary school at Lyons in France in 1761, and the historian can now well discern that elsewhere it made many very bad beginnings. The paramountcy of the horse, which came about with the improvement of road communications early in the nineteenth century, when the Industrial Revolution got into full swing, followed later by decline of the horse which came about early in the present century with the mechanization of road transport, have been major phenomena that have strongly impressed themselves on the trend of developments. The Agricultural Revolution, which coincided with the Industrial Revolution and largely resulted from it, is another phenomenon, the importance of which had been largely masked and ignored in veterinary developments by deflexion of interest, often entirely, to the former one of the ascendancy of the horse. What this Revolution brought in its train was a complete change in the livestock husbandry of Britain and, indeed, of almost all countries, the exceptions being those countries like India and Egypt which still employ cattle mainly as a source 
of motive power in agricultural operations. Otherwise, with the aggregation of large masses of people in towns which needed feeding, and with the enclosure of the commons and the abandonment of the open field system of farming, and, again, with provision for winter feeding of stock, consequent on storage of fodder and introduction of root crops, no less than the temporary absence, as already indicated, of major plagues, the cattle became transformed, largely through the genius of breeders like Robert Bakewell (1725-95) into types that were destined to meet the clamour of the towns for food, namely, meat and milk. England from being a wool- and wheat-exporting country for centuries had now new assets and new outlets, a prime asset being no longer her sheep, and wheat had to become an imported commodity of first magnitude. The invention of refrigeration, which enabled meat supplies to come from abroad, and the improvement of internal transport, so that milch cows need no longer be kept in cities, have again changed the problem confronting the veterinarian, who, paradoxically, with each succeeding change that seemed to foredoom his calling to extinction, has found himself confronted with a transformed yet ever-expanding field for enterprise.

Great triumphs lie already to his credit: in Britain, cattle plague was eradicated, after it was again introduced after a long lapse in 1865, when heed was paid at last to his counsel, so that when in 1870 it reappeared it was promptly eradicated. The legislation introduced at that time laid the foundation for State veterinary control of animal disease in Great Britain. Glanders again was eradicated in 1913; besides, nearly all the other major plagues, like bovine pleuropneumonia, rabies and sheep-pox, had by then been eliminated. Foot-and-mouth disease has been several times eradicated; but difficulties lie in preventing re-introduction with imported animal products. There remains, however, a mass of insidious disesse which is very seriously limiting productivity and is sometimes a grave direct danger to man himself. Tuberculosis has become rampant among our cattle herds; but there seems no reason, particularly in the light of experience gained abroad, in the United States of America, Finland and Norway, why it should not be eradicated in time, effective legislation to bring about that result having been introduced only in 1935. Besides tuberculosis, other serious diseases affecting our dairy herds are sterility, contagious abortion, mastitis and Johne's disease, and much has been achieved already in better understanding of them and devising control. Great success has followed proper investigation, within the last three decades, of the diseases of sheep. Pig diseases are, for the most part, well in hand. In countries abroad, there have been magnificent achievements. Striking examples which may be cited are, first, in the United States, besides the suppression of tuberculosis in cattle, still earlier, following brilliant research, the eradication of Texas fever, a disease which afflicted the southern States to such an extent that economic cattle-raising had become impossible; secondly, wisely guided by the statesmanship of Botha and Smuts after the Boer War, the abundant financial resources available from the Rand were deflected without stint towards ridding the country of animal diseases which were playing havoc with its development as an agricultural country; and, in this endeavour, the successes which attended the labours of the late Sir Arnold Theiler and his disciples exceeded all anticipation.
Knowledge in nearly all departments has so far advanced within the last few decades that we can discern more clearly wherein skill of the kind that is to be derived from a sound veterinary education can be placed at the service of humanity. First, advances in nutritional science have been enormous, and they indicate plainly that a large proportion of the human race lacks adequate and proper feeding, without which there must be physical deterioration inescapably predetermining mental and moral enfeeblement. The stage at which this must be rectified is at the earliest, from conception, the pregnant and nursing mother and young offspring being highly vulnerable towards inadequacy of dietary constituents comprising especially first-class protein and several other substances the richest sources of which are milk, eggs, butter, cheese and other products of animal origin. A standard of living needs to be attained, therefore, at which there shall be no lack of these ingredients, and animal life consequently needs to be safely and economically propagated to meet all requirements. At present, animal life in the world falls very far short of being safe or fully economic to the producers.

Secondly, what to the anthropologist or archæolog. ist has been a minute span of human history, namely, the period since the Industrial Revolution, has been fraught with enormous changes in the relationship of man to his environment, and ecologically it is a grave question whether the powers of any species, including the human species, for readjustment can withstand the strain of such a drastic change. Symptomatic prob. ably of the strain in adjustment is a phenomenon that has come prominently into veterinary experience and, incidentally, proved pecuniarily remunerative, namely, the craving of the urban classes, from the humblest to the richest, for professional attention up. on their household pets-dogs and cats. This source of revenue has more than compensated the profession in England for the disappearance of the horse, and, during the interval between the two world wars, when Government allowed agriculture to lapse almost into a state of insolvency so that farmers could not easily pay for veterinary attention, the newly opened source must have saved the veterinary profession itself, as to a very fair proportion of its members, from dire financial straits. Some social historians have emphasized that the migration of the rural population of England into the towns after the Industrial Revolution was an unmitigated evil, in so far as childhood experience then was not passed, as it had been immemorially, in close relationship with the numbers of other species which the ecologist finds essential for the continuance of any species. All that, of course, awaits inquiry by workers in the several branches of the social sciences. One cannot but be impressed in a country like Egypt, where the great masses of the people-the fellaheen -persist still in a state akin to that of pre-Industrial England, with the serenity of countenance that generally characterizes those masses, compared with the strained, almost tormented, expressions of those inhabitants in the few large cities who are emulating the present urban luxury standards of the West. The maintenance of a numerous and healthy rural population everywhere may therefore prove on proper investigation to be the highest achievement of good statesmanship in the present troubled state of the world; and, interspersed among that population to guide it, will be needed numerous veterinarians. Countries like Holland, Switzerland, Hungary and 
the Scandinavian countries generally have perceived things already in that way and made provision for veterinary education at State expense out of all proportion to what was expended on the "starved and neglected" (to quote departmental committee reports) veterinary colleges in Great Britain in the past.

If one proceeds to make a proper 'job-analysis', then it will be found that to turn out veterinarians to meet the transformed and expanding situation the final objective of the necessary training is three-fold, being concerned with, first, clinical practice ("the doctoring of animals'); secondly, preventive medicine (or public control of the pestilences, grave or insidious, of the kind already mentioned); and thirdly, livestock husbandry and economy (of no less public significance than the former divisions and essential to meet the social circumstances as they are unfolding themselves). A whole array of sciences, many of which have only just emerged as sciences in their own right, such as animal nutrition, genetics, comparative psychology, endocrinology, need to have their proper place in the curriculum of teaching leading to the vocational objectives. Mere minor readjustments in the traditional curriculum are out of place; but what is called for is rather a complete resetting, bearing always in mind the time in the trainee's life that ought not to be exceeded and the expense and the important question of his or her natural aptitude.

Prof. Beveridge in his address has very well perceived many of the implications of the changed situation. The Veterinary Surgeons Act which has just been passed will give him ample freedom within the jurisdiction of a great university to develop his plans, and in all that endeavour he may be well assured of the good wishes and goodwill of his British colleagues. That that university should have thought fit to appoint a countryman of the daughter Dominion of Australia to launch its plans for a complete veterinary education on securing at last full legal sanction to do so is a gesture that will appeal both to the good sense and to the finer sentiments of everyone in Great Britain. Even if space allowed, digression upon the recent history of the several transactions which have ultimately led to the establishment of this teaching at Cambridge would be tedious. However, finally, even in the shortest notice, to omit paying respectful homage to the memory of the late Sir Clifford Allbutt, regius professor of physic at Cambridge, who worked hard during his long life to achieve this end, would be ungracious, now that that end he strove so hard for has come in sight.

\section{OBITUARIES}

\section{Prof. Ruth Benedict}

THE death on September 17 of Ruth Fulton Benedict at the comparatively early age of sixty-one deprives social anthropology of one of its most stimulating writers and thinkers. Ruth Benedict was one of the many American anthropologists who took their early training at Columbia University under the late Franz Boas, and she remained attached to that University all her life, ending her days as the holder of a chair in the Anthropological Department.

Ruth Benedict was a vigorous teacher as well as a woman of distinction and charm. In her youth she did field-work among the Zuni of New Mexico and wrote a series of monographs on them. She will, however, be chiefly remembered for her original and provocative book "Patterns of Culture", published in 1934 ; "Race and Racism", published during the War ; and "The Chrysanthemum and the Sword", an analysis of Japanese character which appeared last year.

The fashion of her day was the conventional type of ethnographic monograph ; but she early cut away from these and marched boldly out on to the frontier between psychology and anthropology. She was interested from the first in the infinite diversity of values and behaviour patterns which are found in cultures of different types. She believed that these ideals and attitudes formed a coherent whole to which she gave the title 'culture pattern'. She suggested that cultures could be grouped into types on the basis of these patterns. Cultures might be deseribed as Apolonian, Dyonisac or Paranoiac, for example, or they could be classified as 'shame' or 'guilt' societies. The individual brought up in such societies was shaped to their dominant pattern.

Ruth Benedict never developed a systematic typology on this basis. Systematic sociology was not the bent of her mind, and her culture pattern concept could not be sufficiently rigorously defined for comparative work of this kind. On the other hand, her imaginative insight and originality sug. gested a new field of problems for a younger generation of anthropologists and psychologists, and her literary gifts made her work available to the general public and very much influenced educationists. She must certainly be reckoned as one of the originators of the study of culture and personality which is such a dominant trend in American anthropology to-day.

Ruth Benedict was deeply interested in contem. porary problems. During the War she used her methods and concepts to provide a study of the culture patterns of the Japanese for the American Office of War Information. At the time of her desth she was engaged in a study of contemporary European cultures, and particularly of their methods of child education. She visited Europe during the past summer and was present at the International Ethnological Congress at Brussels, where she impressed her fellow workers by her vigour and charm. Her death in the middle of an important piece of work will certainly be deeply regretted by anthropologists everywhere.

AUdREY I. RIChaRds

\section{Sir George Hill, K.C.B.}

George Francis Hirl, numismatist, and director of the British Museum during 1931-36, youngest son of Samuel John Hill and grandson of Micaiah Hill, both missionaries in India, was born at Berhampur on December 22, 1867, and educated at Blackheath School, University College School, University College, London, and Merton College, Oxford, where he obtained first classes in Classical Moderations and Literæ Humaniores, and under the influence of Prof. Percy Gardner devoted himself to the study of Greek coins. He entered the British Museum in 1893 , where Barclay Head had recently published bis "Historia Numorum", still the standard text-book in that subject; and edited no less than six volumes of the "Catalogue of Greek Coins". The first of these, on the "Coins of Cyprus" (1897), was followed many years later by a general history of that island, the third volume of which, published in the present year, 